\title{
ANÁLISE DAS SEQÜÊNCIAS DE NUCLEOTÍDIOS DA REGIÃO 5' NÃO CODIFICADORA E DOS GENES DAS PROTEÍNAS ESTRUTURAIS DOS FLAVIVIRUS
}

\author{
NUCLEOTIDE SEQUENCE ALIGNEMENT OF THE 5' NON CODING AND \\ STRUCTURAL PROTEIN REGIONS OF THE GENOME OF FLAVIVIRUSES
}

Luiz Tadeu M. Figueiredo; Corina Karen Dost²; Diane Meyre Rassi²; Fátima Pereira M. Celini²; Glauce Lunardelli Trevisan²; Mânlio Tasso O. Mota²; Márcia Cristina T. Ferreira²; Marcos Lázaro Moreli; Patrícia Cristina G. Pinto²; Renata Dellalibera²; Ricardo Luiz M. Sousa² \& Weber Chelli Batista²

\begin{abstract}
${ }^{1}$ Docente do Departamento de Clínica Médica da Faculdade de Medicina de Ribeirão Preto da Universidade de São Paulo e Coordenador; ${ }^{2}$ Alunos participantes - Curso de Pós-Graduação: Resposta Imune nas Infecções por Vírus (RIM-5720), em 1998.

CorRespondência: Prof.Dr. Luiz Tadeu M. Figueiredo - Unidade Multidepartamental de Pesquisa em Virologia da Faculdade de Medicina de Ribeirão Preto da Universidade de São Paulo; CEP: 14049-900 - Ribeirão Preto - SP - Brasil. E-mail: Itmfigue@fmrp.usp.br
\end{abstract}

FIGUEIREDO LTM et al. Análise das seqüências de nucleotídios da região 5' não codificadora e dos genes das proteínas estruturais dos Flavivirus. Medicina, Ribeirão Preto, 31: 610-615, out./dez. 1998.

RESUMO: Neste trabalho, analisaram-se comparativamente as seqüências de nucleotídios dos genes das proteínas estruturais $\mathrm{C}$, prM e $\mathrm{E}$ de todos os Flavivirus, incluindo, também, a região 5' não codificadora, de 21 Flavivirus. Utilizou-se para a análise o programa de microcomputador DNAsis (Hitachi, Japão) e construiu-se uma árvore filogenética, incluindo os vinte e um (21) vírus, após alinhamento de suas seqüências de nucleotídios. Na árvore filogenética obtida, observou-se uma ramificação inicial, separando os vírus transmitidos por carrapatos daqueles transmitidos por mosquitos. Também, agruparam-se, em diferentes ramos, os vírus do dengue, os da febre amarela, e os da encefalite japonesa. Observou-se uma evidente relação entre a árvore filogenética e os subgrupos e tipos virais, reconhecidos com base em relacionamento antigênico.

UNITERMOS: Flavivirus. Dengue. Alinhamento de Seqüências. Seqüências de Bases.

\section{INTRODUÇÃO}

O gênero Flavivirus, da família Flaviviridae, inclui sessenta e oito (68) membros e possui como protótipo o vírus da febre amarela ${ }^{(1)}$. Estes vírus foram divididos em oito (8) subgrupos com base em relacionamento antigênico, cruzado, utilizando testes específicos de neutralização: Tick-borne encephalitis, Rio Bravo, Japanese encephalitis (aqui estão incluídos os vírus da encefalite de St. Louis, brasileiros), Tyuleniy, Ntaya, Uganda S, Dengue (aqui estão incluídos os vírus do dengue, tipo 1 e 2, brasileiros), Modoc; também, existem pelo menos dezoito (18) Flavivirus não pertencentes aos sete (7) subgrupos ${ }^{(1)}$. Como não grupados, incluem-se os brasileiros, Ilhéus, Rocio, Febre Amarela, Cacipacoré e Iguape ${ }^{(1)}$.

Os Flavivirus são esféricos, envelopados, com projeções na superfície e medem, aproximadamente, 60 nm de diâmetro. Possuem uma fita única de RNA, com peso molecular (PM) de 4 x 10 $0^{6}$, contendo, aproximadamente, 11000 nucleotídeos, a qual comporta-se como RNA mensageiro ${ }^{(2,3)}$.

O RNA dos Flavivirus é de polaridade positiva e codifica dez (10) genes. O terminal 5'do genoma dos Flavivirus possui um "cap" tipo I (m7GppAmp) $)^{(4,5}$, 6). No terminal 3'não possui cauda de poliadenina. Os genes estão presentes no genoma viral, na seguinte ordem: 5'-C-preM-E-NS1-ns2a-ns2b-NS3-ns4a-ns4b- 
NS5-3'. Estão contidos em uma open reading frame, que se inicia no resíduo de metionina, indo até a base 10158 a 10302, dependendo do vírus. Resulta da tradução da open reading frame dos flavivirus uma poliproteína que libera, após clivagens, três (3) proteínas estruturais (C, prM e E) e sete (7) não estruturais (NS1, NS2a e NS2b, NS3, NS4a e NS4b, e NS5). A proteína C, com PM 13 Kilodaltons (Kds), forma, juntamente com o RNA, o capsídio viral, e está codificada entre as bases 99 e 476 do genoma para o JEV, entre as bases 115 e 408 para o YF e entre as bases 115 e 460 para o $\operatorname{TBE}^{(2,4,5,6)}$. A glicoproteína prM possui PM de aproximadamente $18,5 \mathrm{kDa}$ e é precursora da proteína estrutural $\mathrm{M}$, produzida durante o processo de maturação viral. As sequiências codificadoras de prM e M estão codificadas entre as bases 477 e 976 para o JEV, entre 409 e 973 para o YF e entre 461 e 952 para o TBE. A proteína E, com PM $53 \mathrm{Kd}$, e cujo gene contém, aproximadamente, mil, seiscentos e vinte (1620) nucleotídios, codificada entre as bases 977 e 2487 do RNA viral no JEV, entre as bases 974 e 2455 para YF e entre as bases 953 e 2440 para o TBE $(2,4,5,6)$

No Brasil, o vírus silvestre da febre amarela possui macacos (Callitrichida e Cebidae) como reservatórios e a febre é transmitida por mosquitos da copa das árvores, Haemagogos janthinomys e $\mathrm{Ha}$ emagogos leucocelaenus ${ }^{(7,8)}$. Dezenas de casos de febre amarela, muitos deles fatais, são notificados anualmente, na Região Amazônica, Planalto Central e Pantanal ${ }^{(8)}$. A vacina de vírus vivo contra febre amarela 17D, é segura, possui alta capacidade imunogênica e vem sendo extensamente utilizada no mundo todo $^{(9)}$.

Os vírus do dengue, com seus sorotipos 1,2,3 e 4, são considerados os mais importantes arbovírus que acometem o homem. Estes vírus podem causar doença febril, aguda, que acomete milhões de pessoas anualmente, em diferentes regiões do mundo. Também, estes vírus são causa de uma doença grave, a dengue hemorrágica/síndrome de choque do dengue. No Brasil, em 1982, ocorreu um surto de dengue na Cidade de Boa Vista, em Roraima, tendo sido isolados os vírus do tipo 1 e $4^{(10,11)}$. A partir de 1986, grande número de epidemias de dengue vem ocorrendo no país. De março de 1986 a junho de 1996, quinhentos e setenta e nove mil e trinta e sete (579037) casos de dengue foram notificados no Brasil ${ }^{(11,12)}$. Os vírus do dengue tipo 1 e 2 vêm sendo isolados durante estas epidemias brasileiras. Apesar de a maioria dos casos de dengue terem sido benignos, ocorreram muitos casos de dengue hemorrágico, especialmente no Rio de Janeiro e no Ceará ${ }^{(12)}$. Dentre as flaviviroses causadoras de encefalite, destacam-se, dentre outras, a encefalite Japonesa e a do Murray Valley, que ocorre na Austrália. Dentre as arboviroses transmitidas por carrapatos, o vírus Tick-born encephalitis é causa de encefalites no leste europeu. O vírus Powassan faz parte do grupo Tick-born encephalitis, e é encontrado na América do Norte, onde produz casos fatais ${ }^{(2)}$.

A comparação de múltiplas seqüências de nucleotídios de genomas virais ou dos aminoácidos de suas proteínas é um procedimento muito utilizado nos dias atuais e que permite ampla visão sobre a biologia destes microorganismos, auxiliando em três (3) importantes tarefas: dar subsídios para o relacionamento destes vírus em grupos, gêneros, subfamílias e famílias; identificar segmentos com seqüências conservadas e que permitiriam inferências quanto à função de um determinado gene ou, ainda, a seleção de sequiências conservadas para o uso, como sondas ou primers, visando ao diagnóstico destas viroses e, finalmente, a comparação de múltiplas seqüências comuns de nucleotídios de genomas virais permite elaborar uma história da evolução destes microorganismos ${ }^{(13,14)}$.

Objetivou-se, neste estudo, analisar comparativamente as sequiências de nucleotídios dos genes das proteínas estruturais C, prM e E de todos os Flavivirus, incluindo, também, a região 5' não codificadora.

\section{MATERIAL E MÉTODOS}

Escolheram-se, para estudo, as sequiências de nucleotídios de 1 a 2450 dos Flavivirus, principalmente por conter o gene de $\mathrm{E}$, que é a maior proteína do envelope viral. Esta glicoproteína contém os mais importantes determinantes antigênicos virais e possui o receptor que atua no processo de ligação e internalização viral. Da ação de E dependem virulência e características individuais de cada um dos Flavivirus. Portanto, o gene codificador de E possui sequiências variáveis, próprias de cada um dos vírus em estu$\mathrm{do}^{(15,16)}$.

Obtiveram-se, junto ao GenBank dos Estados Unidos (http://www.ncbi.nlm.nih.gov), as seqüências de nucleotídios, da base 1 a 2450, que contém a região 5 ' não codificadora, acrescida dos genes codificadores das proteínas estruturais C, prM, M e E. Foram incluídos no estudo vinte e uma (21) estirpes de Flavivirus, as quais são citadas na Tabela $\mathrm{I}^{(17 / 31)}$. 
Tabela I - Flavivirus incluídos no estudo

\begin{tabular}{|c|c|c|c|}
\hline Vírus & Sigla & $\begin{array}{l}\text { Acesso } \\
\text { GenBank }\end{array}$ & Referência \\
\hline Dengue tipo 1 clone 45AZ5 - PDK27 & D1CL45 & U88537 & DUBOIS DR et al. J Gen Virol 78: 2287-2291, 1997. ${ }^{(17)}$ \\
\hline Dengue tipo 1 clone $45 A Z 5$ & D1Z5 & U88536 & DUBOIS DR et al. J Gen Virol 78: 2287-2291, 1997. ${ }^{(17)}$ \\
\hline Dengue tipo 1 clone WestPac & D1WP & U88535 & DUBOIS DR et al. J Gen Virol 78: 2287-2291, 1997. ${ }^{(17)}$ \\
\hline Dengue tipo 1 Caribbean CV 1636/77 & D1CA & D00501 & CHU MC et al. J Gen Virol 70: 1701-1712, 1989. ${ }^{(18)}$ \\
\hline Dengue tipo 1 Singapore S275/90 & D1SIN & M87512 & FU J et al. Virology 188: 953-958, 1992. ${ }^{(19)}$ \\
\hline Dengue tipo 1 Philippines $836-1$ & $\mathrm{D} 1 \mathrm{PH}$ & D00503 & CHU MC et al. J Gen Virol 70: 1701-1712, 1989. ${ }^{(18)}$ \\
\hline Dengue tipo 1 Nauru Island & D1NAU & M23027 & MASON PW et al. Virology 161: 262-267, 1987. (20) \\
\hline Dengue tipo 1 Thailand AHF82-80 & $\mathrm{D} 1 \mathrm{TH}$ & D00502 & CHU MC et al. J Gen Virol 70: 1701-1712, 1989. ${ }^{(18)}$ \\
\hline Dengue tipo 2 NGc & D2NGc & AF038403 & GUALANO RC et al. J Gen Virol 79: 437-446, 1998. ${ }^{(21)}$ \\
\hline Dengue tipo 2 ThNH-p36/93 & D2TH & AF022441 & MANGADA MN et al. Vírus Genes 14: 5-12, $1997 .{ }^{(22)}$ \\
\hline Japanese encephalitis vírus SA14 & JESA & D90194 & AlHARA S et al. GenBank, 1990. ${ }^{(23)}$ \\
\hline Japanese encephalitis vírus SA14-14-2 & JESA2 & D90195 & AlHARA S et al. GenBank, 1990. ${ }^{(23)}$ \\
\hline Japanese encephalitis vírus Nakaya & JENAK & M16574 & McADA PC et al. Virology 158: $4860,1987 .{ }^{(24)}$ \\
\hline Japanese encephalitis vírus JaOArS982 & JEJAO & M18370 & SUMIYOSHI H et al. Virology 161: 497-510, $1987 .{ }^{(25)}$ \\
\hline Japanese encephalitis vírus & JEV & U15763 & $\mathrm{NI} \mathrm{H}$ et al. J Gen Virol 76: 409-413, 1995. ${ }^{(26)}$ \\
\hline Murray Valley encephalitis vírus & MV & X03467 & DALGARNO L et al. J Mol Biol 187: 309-323, 1986. ${ }^{(27)}$ \\
\hline Powassan vírus & POW & L06436 & MANDL CW et al. Virology 194: $173-184,1993 .{ }^{(28)}$ \\
\hline Tick-borne encephalitis vírus & TBE & X07755 & YAMSHCHIKOV et al. Nucleic Acids Res 16: $7750,1988{ }^{(29)}$ \\
\hline Yellow fever vírus $85-82$ Ivory Coast & YFYC & U54798 & PISANO MR et al. GenBank, 1996. ${ }^{(30)}$ \\
\hline Yellow fever vírus 17D vaccine ATCC \# 234 & YF17D1 & K02749 & DALGARNO L et al. GenBank, $1985 .{ }^{(31)}$ \\
\hline Yellow fever vírus 17D vaccine strain & YF17D2 & X03700 & RICE CM et al. Science 229: 726-733, $1985 .{ }^{(5)}$ \\
\hline
\end{tabular}

Utilizou-se, na análise comparativa das seqüências dos nucleotídios, o programa para microcomputador DNAsis (Hitachi, Japan, 1995) ${ }^{(32)}$. Fez-se o alinhamento das múltiplas seqüências e, em seguida, construiu-se uma árvore filogenética, utilizando-se a técnica de Higgins and Sharp. Para tanto, considerouse como parâmetros os recomendados pelo programa DNAsis (gap penalty $=5$; K-tuple $=2$; No of top diagonals $=5$; window-size $=5$; fixed gap penalty $=$ 10 e float gap penalty $=10$ ). As árvores filogenéticas foram efetuadas segundo o método UPGMA que encontra um ponto médio ideal entre os alinhamentos. Valores percentuais, relacionados ao grau de homologia entre seqüências, são apresentados junto a cada ramo da árvore filogenética ${ }^{(32)}$.

Finalmente, analisou-se a árvore filogenética das seqüências de nucleotídios dos vinte e um (21) Flavivirus e comparou-se a mesma com informações co- nhecidas sobre estes vírus, com base no relacionamento antigênico ${ }^{(1,32)}$.

\section{RESULTADOS}

Como resultado do alinhamento das seqüências de nucleotídios dos dezenove (19) Flavivirus e da comparação entre as mesmas, obteve-se a árvore filogenética, mostrada na Figura 1. O percentual de homologia entre as sequiências genômicas, virais, agrupadas em cada ramo, é mostrado junto à divisão dos mesmos e apresenta valores decrescentes na medida em que estes vão se aproximando da base da árvore. Observam-se altos percentuais de homologia na ponta da árvore, como 86,7\% entre D1WP e D1Z5 e baixos percentuais de homologia na base, como aquele observado entre os Flavivirus transmitidos por mosquitos e os transmitidos por carrapatos, $12,6 \%$. 


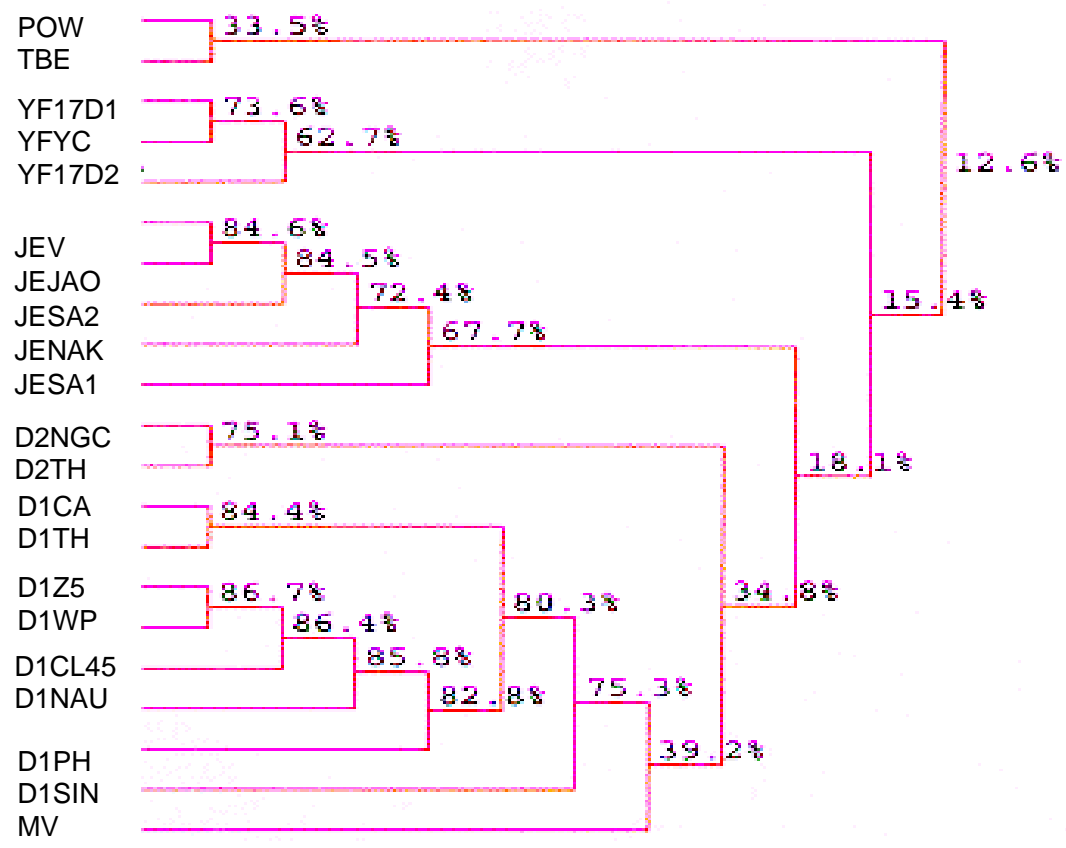

Figura 1 - Árvore filogenética, baseada na comparação das seqüências de nucleotídios (5') 1 a 2450, do genoma de 21 Flavivirus, evidenciando o percentual de homologia entre as seqüências genômicas, virais, agrupadas em cada ramo.

seria representado como a base ou raiz, e as subseqüentes divisões, formando outras espécies, seriam representadas por ramos com sucessivas subdivisões ${ }^{(13,14}$, 32).

Apesar da ocorrência de mais de uma dezena de Flavivirus no Brasil, infelizmente, observou-se que nenhum destes microorganismos tem genoma seqüenciado na extensão requerida para participar deste trabalho. Os dois mil quatrocentos e cinquienta (2450) nucleotídios do genoma dos Flavivirus, selecionados para este estudo, incluem a região 5' inicial não codificadora do genoma e os genes das proteínas estruturais $\mathrm{C}$, PrM, M e E. Portanto, nesta extensa sequiência, espera-se que existam regiões específicas para 0 gênero e para o subgrupo, conforme classificação por testes sorológicos. Também, espera-se

\section{DISCUSSÃO}

O primeiro passo para a comparação de múltiplos genomas consiste no alinhamento dos mesmos segundo o grau de similaridade e distância entre as homologias de suas sequiências. O julgamento destes alinhamentos, muitas vezes, pode ser considerado subjetivo, já que não utiliza funções únicas, explícitas e depende da crítica do avaliador. Nos alinhamentos, procede-se a uma comparação dos nucleotídios par a par, conferindo valores correspondentes às diferenças encontradas e buscando regiões com seqüências comuns. As múltiplas seqüências de nucleotídios de genomas virais, devidamente alinhadas, permitem a construção de árvores filogenéticas, baseando-se nos conceitos aceitos para a evolução da vida, em que todos os microorganismos teriam se originado de um ancestral comum e que novas espécies surgiriam por divisão de populações em 2 ou mais, as quais, caracteristicamente, não conseguiriam reproduzir-se entre si. Espécies de vírus mais relacionadas quanto à evolução seriam aquelas que contêm menos deleções, transições, transversões e outras mutações em suas sequiências. Na árvore filogenética, o ancestral comum a presença de regiões específicas de cada vírus, no gene codificador da proteína $\mathrm{E}^{(33)}$.

$\mathrm{Na}$ árvore filogenética obtida (Figura 1), observou-se uma ramificação inicial, separando os vírus TBE e Powassan dos outros dezenove (19) vírus, com os quais tem apenas uma homologia de $12,6 \%$. Tal fato é facilmente compreensível, sabendo-se que TBE e Powassan são vírus transmitidos por carrapatos e que, portanto, devem ter se diferenciado do anscestral comum, anteriormente aos outros dezenove (19) vírus, todos transmitidos por mosquitos. TBE e Powassan possuem relacionamento antigênico, próximo e são parte do subgrupo Tick-borne encephalitis ${ }^{(1,33)}$. Apesar de apresentarem uma baixa homologia, de 33,5\%, a árvore mostra que os dois vírus originaram-se de um ancestral comum. Estes dois (2) vírus apresentam reatividade cruzada em testes de neutralização altamente específicos e relacionados à resposta de anticorpos contra E.

Formam um ramo, na árvore filogenética, os três (3) vírus da febre amarela incluindo dois (2) da vacina $17 \mathrm{D}$, um deles original da vacina $17 \mathrm{D}$ desenvolvida por Theiler, $1937^{(9)}$, a partir da cepa Asibi africana e seqüenciado por Dalgarno et al. $1985^{(31)}$ e o 
outro, também, do vírus vacinal 17D, seqüenciado em 1985 por Rice et al. ${ }^{(5)}$. Observa-se que um dos vírus vacinais, YF17D1, mostrou maior homologia com o vírus africano YFYC, $(73,6 \%)$ do que com o outro seqüenciamento do vírus vacinal, YF17D2. Tal fato é estranho, sabendo tratar-se YF17D1 e YF17D2 da mesma estirpe viral. Entretanto, provavelmente, YF17D1 e YF17D2 sofreram diferentes números de passagens em diferentes sistemas, o que poderia levar a pequenas mutações genômicas, explicando a redução de homologia.

Dentre os Flavivirus transmitidos por mosquitos, um segundo ramo da árvore filogenética inclui os vírus da encefalite japonesa, os do dengue e o Murray Valley (MV). Separam-se, formando novo ramo, com $18,1 \%$ de homologia, os vírus da encefalite japonesa. Em seguida, ramifica-se o grupo dos vírus do dengue tipo 2 com 34,8\% de homologia. Surpreendentemente, o vírus australiano MV mantém-se mais próximo aos vírus do dengue tipo 1, com 39,2\% de homologia, que do vírus do dengue tipo 2. O MV faz parte do subgrupo encefalite japonesa, com relacionamento antigênico por testes de neutralização e devia-se esperar que agrupasse com os mesmos ${ }^{(1,33)}$. Finalmente, agruparam-se os vírus do dengue tipo 1, com 80,3\% de homologia. Observa-se alta homologia, $84,4 \%$ en- tre a cepa caribenha do dengue tipo 1, a mesma que circula no Brasil, e uma cepa filipina. Dentra as dengue tipo 1, menor homologia foi observada com a cepa viral, isolada em Singapura (D1SIN), 75,3\%.

Observou-se uma evidente relação entre a árvore filogenética obtida com o alinhamento das seqüências dos dois mil, quatrocentos e cinqüenta (2450) nucleotídios do genoma dos Flavivirus estudados e os subgrupos e tipos reconhecidos com base em relacionamento antigênico. Fez exceção apenas o MV, que se agrupou próximo aos vírus do dengue tipo 1. Explica o relacionamento antigênico entre estes vírus a semelhança entre os epítopos de antígenos protéicos, principalmente de $\mathrm{E}$, que induzem a formação de anticorpos de reação cruzada entre estirpes virais. Os epítopos de antígenos protéicos, por sua vez, representam o fenotipo determinado pelos genes das proteínas estruturais, virais, analisadas neste estudo ${ }^{(33)}$.

Estudos com alinhamento e análise de seqüências foram efetuados com todo o genoma de onze (11) Flavivirus, com a região terminal do gene de NS5 e região 3' não codificadora, para setenta e dois (72) destes vírus e com vírus do dengue na região de transição E-NS1. Os resultados obtidos nesses estudos, também, mostram clara correlação com os tipos e subgrupos conhecidos por relacionamento antigênico ${ }^{(34 / 37)}$.

FIGUEIREDO LTM et al. Nucleotide sequence alignement of the 5 ' non coding and structural protein regions of the genome of flaviviruses. Medicina, Ribeirão Preto, 31: 610-615, oct./dec. 1998.

ABSTRACT: In this work, it was comparatively analyzed the nucleotide sequences of the genes of the structural proteins $C$, prM and $E$ of 21 flaviviruses, also including, the 5 ' non codifier area of the genome. The software DNAsis (Hitachi, Japan) was used for the analysis and a phylogenetic tree of the viruses was built, after the alignment of the nucleotide sequences. In the phylogenetic tree an initial ramification separated the viruses transmitted by ticks of those transmitted by mosquitoes. Also 3 different branches of the phylogenetic tree assembled the dengue viruses, the yellow fever viruses, and the Japanese encephalitis viruses. An evident relationship was observed between the phylogenetic tree and the subgroups and types known on the basis of antigenic relationship.

UNITERMS: Flavivirus. Dengue. Sequence Alignement. Base Sequence.

\section{REFERÊNCIAS BIBLIOGRÁFICAS}

1 - WENGLER G. Family Flaviviridae. In: FRANCKI RIB, ed. Classification and nomenclature of viruses - Fifth report of the International Committee on Taxonomy of Viruses. Arch Virol: 230-231, 1991. Suppl. 2
2- MONATH TP. Flaviviruses. In: FIELDS BN \& KNIPE DM, eds. Virology, Raven Press, New York, p.763-814, 1990.

3 - RICE CM et al. Structure of the flavivirus genome. In: SCHLESINGER S \& SCHLESINGER M, eds. The Togaviridae and Flaviviridae, Plenum, New York, p. 279-327, 1986. 
4 - JAN LR et al. Complete nucleotide sequence of the genome of Japanese encephalitis virus Ling strain: the presence of a 25-nucleotide delection in the 3'nontranslated region. Am J Trop Med Hyg 55: 603-609, 1996.

5 - RICE CM et al. Nucleotide sequence of yellow fever virus: implications for Flavivirus gene expression and evolution. Science 229: 726-735, 1985.

6 - MANDL CW et al. Sequence of the structural proteins of Tick-borne encephalitis virus (Western subtype) and comparative analysis with other flaviviruses. Virology 166: 197205, 1988.

7 - SOPER FL. Febre amarela silvestre. Novo aspecto epidemiológico da doença. Rev Hyg Saúde Pública 10: 107144, 1936.

8 - DÉGALLIER $\mathrm{N}$ et al. A comparative study of yellow fever in Africa and South America. J Braz Assoc Adv Sci 44: 143-151, 1992.

9 - THEILER M \& SMITH HH. The use of yellow fever virus modified by in vitro cultivation for human immunization. $\mathbf{J}$ Exp Med 65: 787-800, 1937.

10 - BRASIL, MINISTÉRIO DA SAÚDE - FNS (1995, 1996). Dengue: distribuição de casos notificados por ano e por unidade federada, Brasília, 1996, $10 \mathrm{p}$.

11 - FIGUEIREDO LTM. History, present and future of dengue fever in Brazil. In: TRAVASSOS DA ROSA APA; VASCONCELOS PFC \& TRAVASSOS DA ROSA JFS, eds. An overview of arbovirology in Brazil and neighbouring countries. Evandro Chagas Institute, Belém, p.154-163, 1998.

12 - PRATA A et al. Condutas terapêuticas e de suporte no paciente com dengue hemorrágico. Informe Epidemiológico do SUS 6: 87-101, 1997.

13 - GUSFIELD D. Strings and evolutionary trees. In: GUSFIELD $D$. Algorithms on strings, trees, and sequences, University Press, Cambridge, p.447-479, 1997.

14 - ASUBEL F. Computer manipulation of DNA and protein sequences. In: ASUBEL F, ed. Short protocols in molecular biology, 3th ed, Wiley, New York, p.7.48-7.62, 1997.

15 - BARBOSA ML. Dengue: revisão. Rev Inst Adolfo Lutz 56: 27-45, 1996.

16 - REY FA et al. The envelope glycoprotein from tick-borne encephalitis virus at 2 A resolution. Nature 375: 291-298, 1995.

17 - DUBOIS DR et al. Molecular analysis of dengue virus attenuation after serial passages in primary dog kidney cells. J Gen Virol 78: 2287-2291, 1997.

18- $\mathrm{CHU} \mathrm{MC} \mathrm{et} \mathrm{al.} \mathrm{Genetic} \mathrm{relatadeness} \mathrm{among} \mathrm{structural}$ protein genes of dengue 1 virus strains. J Gen Virol 70: 1701-1712, 1989.

19 - FU J et al. Full-lenght cDNA sequence of dengue type 1 virus (Singapore strain S275/90). Virology 188: 953-958, 1992.

20 - MASON PW et al. Sequence of the Dengue-1 virus genome in the region encoding the three structural proteins and the major nonstructural protein NS1. Virology 161: 262-267, 1987.
21 - GUALANO RC et al. Identification of a major determinant of mouse neurovirulence of dengue virus type 2 using stably cloned genomic - lenght cDNA. J Gen Virol 79: 437-446, 1998.

22 - MANGADA MN et al. Sequences of terminal non-coding regions from four dengue-2 viruses isolated from patients exhibiting different disease severities. Virus Genes 14: 5-12, 1997.

23 - AIHARA S et al. GenBank, D90194, 1990.

24 - McADA PC et al. Partial nucleotide sequence of the Japanese encephalitis virus genome. Virology 158: 1860-1868, 1987.

25 - SUMIYOSHI H et al. Complete nucleotide sequence of the Japanese encephalitis virus genome RNA. Virology 161: 497-510, 1987.

26 - $\mathrm{NI} \mathrm{H}$ et al. Molecular basis of attenuation of wild-type Japanese encephalitis viru strain AS-14. J Gen Virol 76: 409413, 1995.

27 - DALGARNO L et al. Partial nucleotide sequence of Murray Valley encephalitis virus genome - comparison of the encoded polypeptides with yellow fever virus structural and non-structural proteins. J Mol Biol 187: 309-323, 1986.

28 - MANDL CW et al. Complete genomic sequence of Powassan virus: evaluation of genetic elements in tick-borne versus mosquito-borne flaviviruses. Virology 194: 173-184, 1993.

29 - YAMSHCHIKOV et al. Nucleotide sequence of the genomic region encoding the structural proteins and the NS1 protein of the tick-borne encephalitis virus. Nucleic Acids Res 16: 1750-1760, 1988.

30 - PISANO MR et al. GenBank, U54798, 1996.

31 - DALGARNO L et al. GenBank, K02749, 1985.

32 - DNASIS for Windows - Sequence analysis software Manual. Hitachi, Japan, 1995.

33 - CALISHER $\mathrm{CH}$ et al. Antigenic relationships between flaviviruses as determined by cross - neutralization tests with polyclonal antisera. J Gen Virol 70: 37-43, 1989.

34 - TANAKA $M$ et al. Homology among eleven Flavivirus by comparative nucleotide sequence of genomic RNAs and deduced amino acid sequences of viral proteins. Trop Med 33: 23-33, 1991.

35 - KUNO G et al. Phylogeny of the genus Flavivirus. J Virol 72: 73-83, 1998.

36 - RICO-HESSE R. Molecular evolution and distribution of dengue viruses type 1 and 2 in nature. Virology 174: 479-493, 1990.

37 - THANT KZ et al. Sequences of E/NS1 gene junction from four dengue-2 viruses of Northeastern Thailand and their evolutionary relationships with other dengue-2 viruses. Microbiol Immunol 39: 581-590, 1995.

Recebido para publicação em 06/07/98

Aprovado para publicação em 10/11/98 